\title{
Evaluation of Pattern of Infertility Among The Patients of A Selected Infertility Center in Dhaka, Bangladesh
}

\author{
Hossain $\mathrm{SM}, \mathrm{PhD}^{1}$,Khaliduzzaman SM, MPH ${ }^{2}$, Huq S, $\mathrm{MPH}^{3}$, Sharmin UH, \\ $\mathrm{MPH}^{4}$, Eusufzai SZ, MPH ${ }^{5}$, Jamayet NB, M.Sc.Dent ${ }^{6}$, \\ ${ }^{1}$ Professor and Head, Department of Public Health, Northern University Bangladesh. \\ ${ }^{2}$ Embryologist, Apollo Hospital Dhaka. \\ ${ }^{3}$ Lecturer, Department of Public Health, Northern University Bangladesh. \\ ${ }^{4}$ Resident Medical Officer, Apollo Hospital Dhaka. \\ ${ }^{5}$ Senior Lecturer, Dental Public Health Unit, School of Dental Sciences, UniversitiSains Malaysia, Kota Bharu, \\ Kelantan, Malaysia. \\ ${ }^{6}$ Senior Lecturer, Maxillofacial Prosthetics Unit, School of Dental Sciences, UniversitiSains Malaysia, Kota \\ Bharu, Kelantan, Malaysia.
}

\begin{abstract}
Background and Objective: To become a biological parent is the long cherished desire of all couples. It is the pivot for a loving, successful family. The objective of the study is to assess the factors affecting fertility among the patients attending a selected infertility centre in Dhaka city.

Methods: A descriptive type of cross sectional study was carried out with 160 samples by using non-randomized purposive sampling technique and data collection was done by a pretested and modified questionnaire. Data were analyzed by SPSS (version 16).

Results: The study revealed that among the respondents $68.1 \%$ was between age group 26-35 years with mean age $32.38 \pm 4.884$ years. Among them $63.7 \%$ completed their graduation and masters, 50.6\% had a monthly family income as BDT 10,000-50,000. Of the respondents $45 \%$ was smoker and $66.6 \%$ used to take $<5-10$ sticks per day. Study also revealed that $38.5 \%, 37.7 \%, 24.4 \%$ and $4.1 \%$ of the respondents haddepression, job stress, and partner relationship problems respectively. Study also found that hypertension, diabetes, mumps, undescendent testes was reported by $36.5 \%, 26.9 \%, 5.7 \%$ and $2 \%$ of the respondents respectively. Approximate $28.9 \%, 44.7 \%, 21.1 \%$ and $5.3 \%$ of the respondents experienced tubal, ovarian, uterine and accidental surgery respectively. Among all the female respondents $91.2 \%, 26.8 \%, 12.6 \%$ did ovulation induction, IUI, IVF respectively. Of them $79.1 \%, 86 \%$ and $95 \%$ failed to conceive after getting consecutive treatment. Statistical association was found between satisfactory relationship among couple and less duration of infertility treatment $(p=0.04)$.
\end{abstract}

Conclusion: Infertility has become a global challenge at present time; to overcome the problem mass awareness has to be created with availability of effective treatment facilities within reach.

Keywords: Infertility, Satisfactory relationship, Induction, IVF

\section{Introduction}

To become a proud biological parent has never been so important than any other story in life. Normal fertility is usually defined as achieving a pregnancy within 2 years of regular coital exposure. However, $8-10 \%$ of couples experiences some form of infertility problem world-wide.There are many biological causes of infertility including some that medical intervention can help. ${ }^{[1]}$ Infertility has increased by $4 \%$ since 1980 s, mostly from problems with fecundity due to an increase in age. ${ }^{[2]}$ About $40 \%$ of the issues involved with infertility are due to the man, another $40 \%$ due to the woman, and $20 \%$ from complications with both partners. ${ }^{[3]}$ Women who are fertile experience a natural period. Although the prevalence of infertility has probably remained constant in the last two decades. However, number of patients visiting to fertility centers had increased dramatically all over the world, especially for the last 10 years in Bangladesh ${ }^{[4]}$ It was an important milestone with the announcement of the birth of Louise Brown in July 6, 1978, which was beginning of Invitrofertilization (IVF). Now a days the practicing infertility specialist and gynecologist getting the patients with the following problems; e.g. Anovulation, Tubal problem, Polycystic ovary, Endometriosis, Lifestyle problem, Endometrial polyp, Recurrent Abortion,Induced abortion then fertility problem, Uterine factor, cervical and vaginal problem. In case of male partner most of the problem is with oligo-asthenozoospermia then Azoospermia, unable to perform intercourse and decreased libido. Some patients are coming while taking some sorts of medication, some are with varicocele repair and there are some operational history. ${ }^{[5-7]}$ Invitro Fertilization (IVF) is the best treatment so far developed for infertile couples. ${ }^{[8]}$ In July 1978 Patrick Steptoe and 
Edwards first achieved successful human IVF pregnancy. ${ }^{[9]}$ However the first test tube baby was born in Bangladesh on December 14, 2003. It was only one center at that time in Bangladesh.But nowa day the number of centers rising inall over the world as well as in Bangladesh. ${ }^{[10-12]}$ On the other hand number of patients is also rising.They are attending the fertility centers here and there. ${ }^{[13-14]}$ Infertility was a neglected issue in the reproductive health policy of this country, rather the emphasis had always been on the problem of overpopulation. Yet the dominant state ideology in Bangladesh is related to controlling fertility and the implementation of Family Planning program has become a success story. ${ }^{[15]}$ Despite females' inability to reproduce child and even sex of child born resultanegative impact, sometimes with husband and always with other family members leading to destabilization of her social status. ${ }^{[16]}$ Interactions with husband, friends and family are altered and therefore lead to an altered experience of self. ${ }^{[17]}$ Emotional harassment is commonly experienced by a large number of such women in their marital homes in the form of ostracism from family celebrations, taunting and stigmatization, negative attitude as well as beating, withholding of food and health care. $^{[18]}$

This paper describes the medical condition of infertility exists at the crossroads of personal and societal domains, how are they presenting to physician with bad experiences like consequences of childlessness. It will also emphasize to provide an overview of the socio-cultural and epidemiological elements of infertility and examine the arguments for considering infertility as an issue of public health significance.

\section{Materials and Methods}

It was a descriptive type of cross-sectional study. The study population was all the infertile population within reproductive age group and sample was drawn from among those groups who visited Apollo Hospital, Dhaka due to infertility problem at the time of data collection. The study was conducted from January 2013 to April 2013. All infertile female of reproductive age group and women who failed to conceive within a year of fully unprotected regular intercoursewith the consent of the husband was included in the study . All couples who were not available at the time of data collection and who decidednot to participate in the study was excluded from the study. Non-randomized purposive sampling technique was adopted to draw sample from the study population. All the data were collected by semi-structured, pretested and modified questionnaire by face to face interview. The collected data was edited by checking, cleaning and analyzing by using the software SPSS 16.0 version. Result is presented by frequency and cross tabulation analysis. The association was found by using Pearson's chi-square test.

\section{Results}

Study findings showed that among the participants $68.1 \%$ was in age group 26-35 years followed by $23.7 \%$ in $36-45$ years, $6.8 \%$ in $15-25$ years with mean age $32.38 \pm 4.884$ years. Among all the respondents $63.7 \%$ completed their graduation and above degrees, $23.1 \%$ was HSC passed, $10 \%$ was SSCpassedand $3.2 \%$ studied up to primary level. Half of the respondents $(50.6 \%)$ had a monthly family income as BDT 10,00050,000 followed by $45.5 \%$ as BDT $50,001-100,000,3.9 \%$ as BDT $100,001-150,000$. All these sociodemographic data are presented in table no 1 . It was also seen that $45.0 \%$ of the respondents had smoking habit and rest $55.0 \%$ did not smoke. Among the smokers $19.4 \%$ took $<5$ sticks per day, $66.6 \%$ and $13.8 \%$ took $<5-10$ and $<10$ sticks per day(Table 2).More than half of the respondents $(56.2 \%)$ were not stressed in their life and rest of them $43.8 \%$ were stressed in life. Among them who had stressed life $38.5 \%, 37.7 \%, 24.4 \%$ and $4.1 \%$ mentioned that the reasons of their stress are self-depression, jobs stress, family problem and partner related problem respectively (Table 3).Among all the respondents $36.5 \%$ reported that they are suffering from Hypertension, 26.9\% said that they have Diabetes, 5.7\% suffered from Mumps and 2\% had undescendent testes. (Figure 1)

Surgical intervention was also reported by the respondents in a manner like $28.9 \%, 44.7 \%, 21.1 \%$ and $5.3 \%$ had Tubal surgery, Ovarian surgery, Uterine surgery and Accidental surgical cases respectively(Figure 2). In Bangladesh infertility treatment has become very expensive nowadays. Despite a bulk of the respondents (91.2\%) took ovulation induction and among them 60.5\% took it for 6-12 times, $22.5 \%$ women tried it for $>12$ times and $17 \%$ had $<6$ cycles of ovulation induction. Those who took induction $20.9 \%$ conceived and $79.1 \%$ failed to conceive. But intra uterine insemination was done by $26.8 \%$ of the respondents where majority $(73.2 \%)$ did not go for it. Those who went for it only $14 \%$ got positive result and $86 \%$ did not conceived. Invitrofertilization which is considered to be the most expensive infertility treatment was attempted by only $12.6 \%$ of the respondents whereas $87.4 \%$ did not go for it. Among those only 5\% become pregnant and $95 \%$ didn't become pregnant after doing IVF (Table 4).Statistical association was found between relationship among couple and duration of infertility treatment $(\mathrm{p}=0.04)$, (Table 5). 
Table No 1: Distribution of the respondents by Socio-demographic variables

\begin{tabular}{|l|l|}
\hline Variables & Percentage (\%) \\
\hline Age & \\
\hline $15-25$ & 6.8 \\
\hline $26-35$ & 68.1 \\
\hline $36-45$ & 23.75 \\
\hline $46-55$ & 1.2 \\
\hline Mean $\mathbf{\text { SD }}=\mathbf{3 2 . 3 8} \mathbf{+ 4 . 8 8 4}$ \\
\hline Education & \\
\hline Primary & 3.2 \\
\hline SSC & 10 \\
\hline HSC & 23.1 \\
\hline Graduate \& Above & 63.7 \\
\hline Monthly Income & \\
\hline $10000-50000$ & 50.6 \\
\hline $50001-100000$ & 45.5 \\
\hline $100001-1000000$ & 3.9 \\
\hline
\end{tabular}

Table No 2: Distribution of the respondents by smoking history

\begin{tabular}{|l|l|}
\hline Variables & Percentage\% \\
\hline Smoking habit & \\
\hline Yes & 45.0 \\
\hline No & 55.9 \\
\hline Cigarettes/day & \\
\hline$<5$ sticks per day & 19.4 \\
\hline$<5-10$ sticks per day & 66.6 \\
\hline$<10$ sticks per day & 13.8 \\
\hline
\end{tabular}

Table No 2: Distribution of the respondents by Stressful life

\begin{tabular}{|l|l|}
\hline Variables & Percentage \% \\
\hline Stressful Life & \\
\hline Yes & 43.8 \\
\hline No & 56.2 \\
\hline Reasons for stress & \\
\hline Depression & 38.5 \\
\hline Job stress & 37.7 \\
\hline Family problem & 24.4 \\
\hline Partner related problem & 4.1 \\
\hline
\end{tabular}

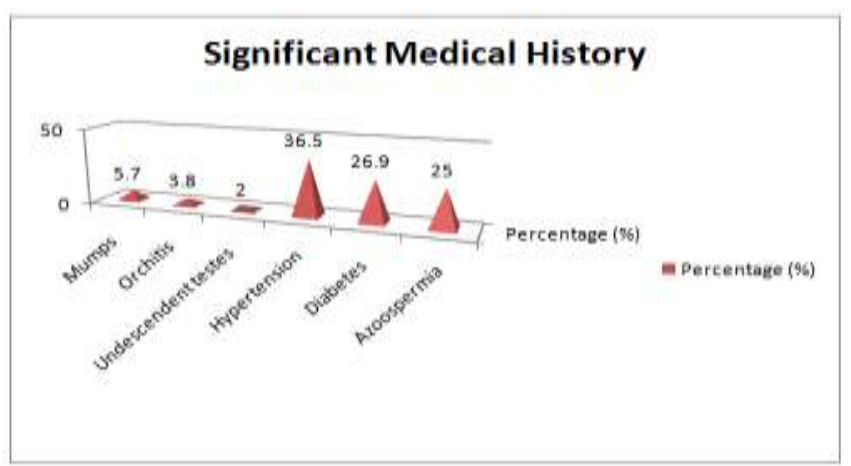

Figure No 1: Distribution of the respondents by Significant Medical History

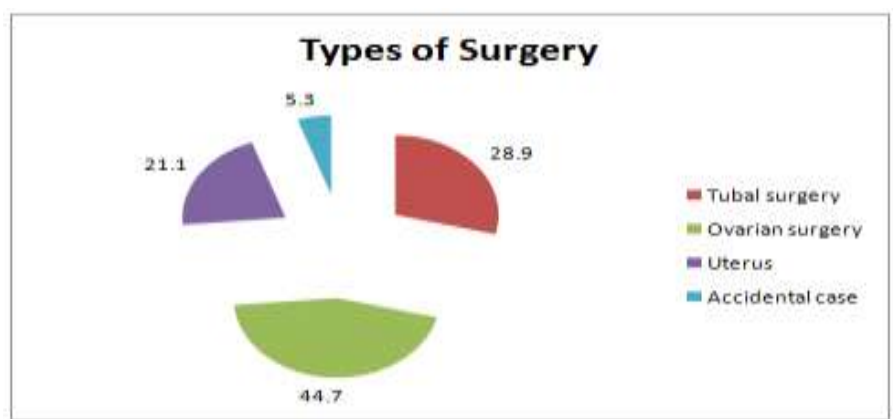

Figure No 2: Distribution of the respondents by type of lower abdominal surgery 
Table No 3: Distribution of the respondents by Infertility treatments and their outcomes

\begin{tabular}{|l|l|}
\hline Variables & Percentage \% \\
\hline Ovulation Induction & \\
\hline Yes & 91.2 \\
\hline No & 8.8 \\
\hline Cycle of induction & \\
\hline$<6$ & 17 \\
\hline $6-12$ & 60.5 \\
\hline$>12$ & 22.5 \\
\hline Outcome of induction & \\
\hline Conceived & 20.9 \\
\hline Failed to conceive & 79.1 \\
\hline Intra Uterine Insemination (IUI) & \\
\hline Yes & 26.8 \\
\hline No & 73.2 \\
\hline Outcome of IUI & \\
\hline Conceive & 14 \\
\hline Failed to conceive & 86 \\
\hline IVF treatment & \\
\hline Yes & 12.6 \\
\hline No & 87.4 \\
\hline Outcome of IVF & \\
\hline Conceived & 5 \\
\hline Not conceived & 95 \\
\hline
\end{tabular}

Table No 4: Distribution of the respondents by Association between relationship among couple and duration of infertility treatment.

\begin{tabular}{|c|c|c|c|c|c|c|}
\hline \multirow[t]{2}{*}{$\begin{array}{l}\text { Relationship } \\
\text { among couples }\end{array}$} & \multicolumn{5}{|c|}{ Duration of infertility treatment (in year) } & \multirow[t]{2}{*}{ p-Value } \\
\hline & 1 & 1-2 & 3-5 & $>5$ & Total & \\
\hline Satisfactory & 40 & 34 & 12 & 1 & 87 & \multirow[t]{3}{*}{0.043} \\
\hline Not satisfactory & 33 & 17 & 20 & 3 & 73 & \\
\hline Total & 73 & 51 & 32 & 4 & 160 & \\
\hline
\end{tabular}

\section{Discussion}

The present cross-sectional study evaluates the pattern of infertility among the patients attending OPDfertility clinic of Apollo Hospitals Dhaka. Various socioeconomic variables were discussed in the result section. Some of these findings were such as majority of the participants (68.1\%) were in age group 26-35 years followed by $23.7 \%$ in $36-45$ years, $6.8 \%$ in $15-25$ years with mean age $32.38 \pm 4.884$ years. Among all the respondents $63.7 \%$ were completed their graduation and above degrees, $23.1 \%$ was HSC passed, $10 \%$ was SSC and $3.2 \%$ up to primary passed respectively. Half of the respondents' $(50.6 \%)$ monthly family income was BDT 10000-50000 followed by $45.5 \%$ had BDT 50001-100000, 3.9\% had BDT 100001-150000. It was also seen that $45.0 \%$ of the respondents had smoking habit and rest $55.0 \%$ did not smoke. Among the smokers $19.4 \%$ took $<5$ sticks per day, $66.6 \%$ and $13.8 \%$ took $<5-10$ and $<10$ sticks per dayrespectively. Some of these findings are almost closer to the findings of a study done by Bulletti $\mathrm{C}$ et al. ${ }^{[19]}$

Among the respondents $43.8 \%$ had stressed life, 38.5\%, 37.7\%, 24.4\% and $4.1 \%$ mentioned that the reasons of their stresswereas depression, jobs stress, family problem and partner related problem respectively. Among all the respondents 36.5\% reported that they had been suffering from Hypertension, 26.9\% from Diabetes, $5.7 \%$ from Mumps and 2\% had undescendent testes. Surgical intervention was also reported by the respondents like $28.9 \%, 44.7 \%, 21.1 \%$ and $5.3 \%$ had Tubal surgery, ovarian surgery, uterine surgery and Accidental surgery respectively. Exactly similar findings were not available in any other study so far reviewed, so it is correlated here with emphasis that stressful life or significant medical history and some sorts of surgerymight interfere with fertility.

Infertility treatment is now very expensive in Bangladesh. In spite ofsuch limitation91.2\% of the respondents took ovulation induction and among them only $20.9 \%$ conceived and $79.1 \%$ failed to conceive. But intra uterine insemination was done by $26.8 \%$ of the respondents where only $14 \%$ got positive result. Invitrofertilization which is considered to be the most expensive infertility treatment was attempted only by $12.6 \%$ of the respondents whereas $87.4 \%$ did not go for it. Among those only 5\% become pregnant and $95 \%$ didn't become pregnant after doing IVF. Quite similar findings were found in a study done in 2003 by Smith C et al. ${ }^{[20]}$ Statistical association was found between relationship among couple and duration of infertility treatment $(\mathrm{p}=$ 0.04).

Key Points:

$>$ To become a biological parent is the long cherished expectation of all couples.

$>$ Infertility has become a global challenge at present time. 
$>\quad 8-10 \%$ of couples experiences some form of infertility problem world-wide.

$>$ Infertility remains a neglected issue in Bangladesh's reproductive health policy.

$>$ The first test tube baby was born in Bangladesh December 14, 2003.

\section{Conclusion}

A thorough but time-efficient investigation of the infertile couple is required prior to a diagnosis of unexplained infertility. Couples should undergo a semen analysis, ovulation testing, assessment of ovarian reserve, and imaging to assess for tubal and uterine factors before a diagnosis of unexplained infertility is made. This workup can be completed within 1 menstrual cycle. In case of couples with unexplained infertility, various treatment modalities are available including expectant management with lifestyle changes, operative laparoscopy, $\mathrm{COH}$ (clomiphene citrate or gonadotropins) with IUI, and IVF (with or without ICSI). The optimal treatment strategy needs to be based on individual patient characteristics such as age, treatment efficacy, sideeffect profile such as multiple pregnancy, and cost considerations. However, no stone to be left unturned to make the mother fertile and return the smile on the face of the family.

\section{Recommendations}

1. Infertility should be treated as a public health problem.

2. To create awareness among the affected population so that they report to fertility expert in time.

3. Government should come forward with a basic policy change to create effective fertility center.

[1]. Himmel W, Ittner E, KochenMM, Michelmann HW, Hinney B, Reuter M, et al. "Voluntary Childlessness and being Childfree". British Journal of General Practice 1997, 47 (415): 111-8.

[2]. Collins JA, So Y, Wilson EH, et al. The postcoital test as a predictor of pregnancy among 355 infertile couples. FertilSteril. 1984; 41:703-708.

[3]. Abma JC, Chandra A, Mosher WD, et al. Fertility, family planning, and women's health: new data from the 1995 National Survey of Family Growth. Vital Health Stat 23. 1997;19:1-114

[4]. Paul C A, Karl K, Alexandra H F, Jeffrey D K, Arthur L R, and Purnima M. Prevalence \& correlates of primary infertility among young women in Mysore, India. Indian J Med Res. 2011 October; 134(4): 440-446.

[5]. Infecundity, infertility and childlessness in developing countries. DHS Comparative Reports No 9. Calverton, Maryland, USA: ORC Macro and the World Health Organization; 2004. World Health Organization.

[6]. Sciarra J. Infertility: an international health problem. Int J Gynaecol Obstet. 1994;46:155-63.

[7]. Looking back, looking forward: a profile of sexual and reproductive health in India. New Delhi: Population Council; 2004. Population Council. Infertility; pp. 67-72.

[8]. Fathalla MF. Reproductive health: a global overview. Ann NY Acad Sci. 1991;626:1-10.

[9]. Van B F, Gerrits T. Quality of infertility care in poor-resource areas and the introduction of new reproductive technologies. Hum Reprod. 2001;16:215-9.

[10]. Ombelet W, Cooke I, Dyer S, Serour G, Devroey P. Infertility and the provision of infertility medical services in developing countries. Hum Reprod Update. 2008;14:605-21.

[11]. Reproductive health indicators for global monitoring: Report of the second interagency meeting, 2001. Geneva: World Health Organization; 2001. World Health Organization;p- 23.

[12]. Inhorn MC. Global infertility and the globalization of new reproductive technologies: illustrations from Egypt. SocSci Med. 2003;56:1837-51.

[13]. Ericksen K, Brunette T. Patterns and predictors of infertility among African women: a cross-national survey of twenty-seven nations. SocSci Med. 1996;42:209-20.

[14]. Cates W, Farley TM, Rowe PJ. Worldwide patterns of infertility: is Africa different? Lancet. 1985;2:596-8.

[15]. Ahmed SM, Chowdhury AMR, Ahmed M. (ed.) Bangladesh towards 21st Century. Dhaka: Community Development Library; 1999. Health scenario; pp. 55-78.

[16]. Swan SH, Liu F, Overstreet JW, Brazil C, Skakkebaek NE. Semen quality of fertile US males in relation to their mothers' beef consumption during pregnancy Hum Report, 200722 (6):1497-1502.

[17]. US national health statistics .Fertility of men and women aged14-44 years in United States; 2012. Available from: http://www.cdc.gov/nchs/govdelivery.htm.(Cited on 20th november2013).

[18]. Carr BR, Blackwell RE.Epidemiologic and etiologic aspects of primary infertility in the Kashmir region of India.Fertility and Sterility, October 1997 68(4): 637-643.

[19]. Bulletti C, Coccia ME, Battistoni S, Borini A (August 2010). Endometriosis and infertility. J. Assist. Reprod. Genet.27 (8): 441-7.

[20]. Smith C, Grimm M andSchwegelM. Treatment of infertility in women.J Am Pharm Assoc (2003) 2012; 52: 27-42. 